\title{
EU research ministers lean on Brussels
}

[LONDON \& MUNICH] The European Commission is coming under pressure from member states of the European Union (EU) to impose tighter constraints on research projects to be funded under the fifth Framework programme (FP5), and to reduce its proposed emphasis on untargeted generic and basic research.

Their demands are contained in letters which are being sent to Brussels containing the comments of the various governments on the commission's latest draft proposals on FP5, which is due to last from 1999 to 2003 , with a budget of more than ECU15 billion (US $\$ 13.2$ billion).

Unsurprisingly, some of the strongest criticism has come from the United Kingdom. Ian Taylor, Britain's minister for science, has written to Edith Cresson, the commissioner responsible for research, arguing against supporting any generic research that is not linked to targeted 'key actions'.

But Britain is not alone. Several other countries have expressed similar concern that, as the FP5 proposals stand, the goals of its research programmes are not sufficiently focused. The programmes reflect Cresson's desire to see that EU research projects meet a set of broadly defined social goals.

Germany is pressing for the 'key actions' proposed by the commission to have much sharper goals. Like Britain, it wants the com- mission to set up advisory panels that would help to produce a precise description of such actions and to oversee their implementation.

Much of the criticism from EU states focuses on the commission's proposal that there should only be three main 'thematic programmes', aimed respectively at the sciences of the living world and the ecosystem, the 'user-friendly information society', and competitive and sustainable growth (see Nature 386, 5; 1997).

Several countries argue that the number of thematic programmes should be increased to between five and seven. Some argue that there should be thematic programmes devoted to the problems of environmental pollution and the life sciences. Another proposal is for a programme devoted to energy needs. Germany suggests that this should include two specific 'key actions', one aimed at the development of efficient, high-performance power plants with low carbon dioxide emissions, and the other on solar heating of buildings.

A second area of contention is the commission's proposal that it should set aside part of the funds for FP5 to support "general activities for the development of generic technologies and basic research". The commission argues that this is needed to develop the EU's general scientific and technological capability, but several member states say that this goal can be achieved more effectively by channelling funds through national agencies.

Taylor of the United Kingdom, for example, expresses disappointment that the proposed focus on 'key actions' is being "potentially undermined" by the "continuing parallel emphasis" in the commission proposal on broadly based, non-targeted general activities for the development of generic technologies and basic research.

Germany wants basic research to be removed from the funds allocated to generic technology, and for such research to be funded only as a component of key actions.

France is believed to share many of Britain and Germany's concerns about the apparent breadth of the proposals. French officials are also said to be less insistent than they were previously that FP5 should allocate a substantial fraction of its funds to basic research, apparently accepting that it is more appropriate for such funds to be distributed nationally.

Drawing on the comments it is receiving, the commission is planning to produce a final draft of its FP5 proposals before mid-April. This will be submitted for approval both to the Council of Ministers - representing member states - and to the European Parliament. Agreement must be reached between all three bodies before the programme can proceed.

DavidDickson \& Alison Abbott

\section{Political constraints restrict moves to conserve fish stocks}

[LONDON] European fisheries and environment ministers ended a two-day meeting in Bergen, Norway, last week on protecting North Sea fish stocks by agreeing that urgent steps are needed to stop overfishing - but they failed to agree on a timetable for action.

The final declaration was a compromise between environment ministers, who favour prompt action, and the fisheries directorate of the European Commission, whose officials had pointed out that the European Union's Common Fisheries Policy remains the only legal mechanism for changing fishing practices.

Environmental groups and other observers believe that this restriction, if applied rigorously, renders the ministerial statement little more than "a pious form of words", as the fisheries policy is not due for review for five years.

The lack of specific targets and deadlines to combat overfishing, as well as the fact that the ministers' statement carries no legal force, prompted a chorus of derisory comments from environmental groups. But there was praise for Denmark, whose environment minister, Svend Auken,

\section{IMAGE UNAVAILABLE FOR COPYRIGHT REASONS}

Caught in the act: Greenpeace protests.

announced that his country would suspend industrial fishing in "sensitive" areas.

A joint statement by Greenpeace, the World Wide Fund for Nature, BirdLife International and Seas at Risk says the declaration remains fundamentally flawed. "None of the actions can be achieved without precise targets and the reintroduction of specific deadlines."

Lord Perry of Walton, a member of the UK House of Lords Select Committee on
Science and Technology, says the only hope now is for governments to lobby for an earlier review of the Common Fisheries Policy. "The United Kingdom takes over the presidency of the EU shortly. One of the first things we should do is to push for the review to be advanced to 1998 or $1999 . "$

The Lords committee reopened hearings on the fisheries issue two weeks ago, one year after its report on fish stocks management called for an immediate 30 per cent reduction in fishing.

Lord Selborne, the committee's chairman, said in a recent letter to the UK fisheries minister that, despite the report's warning of the dangers of overfishing, present EU fisheries policies displayed "a lack of urgency".

Unsustainable fishing is now a serious problem in the North Sea. Increasingly powerful fleets are catching younger and younger fish, often before they have time to reproduce, which has led to a crisis in the cod population (see Nature 385, 521-522; 1997).

Each EU country is assigned a 'catch quota' under the joint fisheries policy. But quotas are difficult to adhere to, as nets tend to catch a variety of species. 